\title{
DIAGNOSIS AND TREATMENT OF PROSTATIC ABSCESS
}

\author{
PAULO OLIVEIRA, JUAREZ A. ANDRADE, HELDER C. PORTO, JOSÉ E. PEREIRA FILHO, \\ ANTÔNIO F. J. VINHAES
}

Section of Urology, São Rafael Hospital, Salvador, Bahia, Brazil

\begin{abstract}
Objectives: Present and discuss the pathogenesis, diagnostic methods and treatment of the prostatic abscess.

Materials and methods: We have retrospectively studied the medical records of 9 patients diagnosed and treated for prostatic abscess, between March 1998 and December 2000, assessing age, context, associated diseases, and diagnostic and therapeutic methods. We have compared the data found with those described in literature, based on Medline data.

Results: Mean age was 52.6 years. Three patients had previous diabetes mellitus diagnosis, and one was infected by HIV virus. Transrectal ultrasound of the prostate confirmed the diagnosis of prostatic abscess in all 7 cases in which it was performed. All cases received antibiotic treatment, and $77.8 \%$ needed concomitant surgical treatment. Two cases of microabscess were treated only with antibiotics. Four patients were submitted to perineal catheter drainage, 2 were submitted to transurethral resection of the prostate (TURP), and one patient required both procedures. Mean hospitalization time was 11.2 days, and most frequent bacterial agent was S. aureus. All patients were discharged from the hospital, and there was no death in this series.

Conclusions: Prostatic abscess should be treated with broad-spectrum antibiotics and surgical drainage (perineal puncture or TURP). Microabscess may heal without surgery.
\end{abstract}

Key words: prostate; infection; abscess; diagnosis; therapeutics

Int Braz J Urol. 2003; 29: 30-4

\section{INTRODUCTION}

The prostatic abscess is difficult to diagnose, because at the symptoms onset it may mimic several other diseases of the lower urinary tract. It is uncommon, and rarely diagnosed, and it has suffered a great shift in its mortality rate, and in the types of etiologic agents observed since the discovery and use of penicillin (1). In the forties, mortality ranged from $6 \%$ to $30 \%$, and major microorganism involved was Neisseria gonorrhea. More recent data suggests a mortality rate from $3 \%$ to $16 \%$ (2), enterobacteria being the most common agents. Among these, Escherichia coli has the highest prevalence, in about $70 \%$ of the cases (3).
In this paper we present data about 9 patients diagnosed with prostatic abscess, discussing clinical findings, diagnostic criteria, and treatment results.

\section{MATERIALS AND METHODS}

We have retrospectively studied a series of 9 patients admitted to, and treated in, our facility, between March 1998 and December 2000, with diagnosis of prostatic abscess. The data was collected in the medical records. Literature review was based on Medline data.

Age ranged from 37 to 73 years (mean 52.7). Four patients had risk factors. One was an intravenous drug user with 7 years asymptomatic HIV in- 
fection and the prostatic abscess was concomitant to a perirenal abscess. Three had diabetes, and one presented the prostatic abscess after a prostatic biopsy. All were treated with parenteral antibiotics. Surgical treatment was indicated in cases where there was no clinical improvement with antibiotic therapy, and after confirming the diagnosis of prostatic abscess. The criteria of hospital discharge were absence of fever for at least 48 hours, and leucogram normalization.

\section{RESULTS}

Symptoms consistent with prostatitis initiated the clinical context, and 7 patients (those with the largest abscess) progressed with urinary retention. Two patients presented previously lower urinary tract symptoms, but there was a worsening of the symptoms, suggesting acute prostatitis. Besides 4 patients with previous diseases altering the immune system (case 1 - HIV infection and cases 4, 6 and 7 - diabetes), 2 also presented possible primary focuses of bacterial haematogenous dissemination (case 1 presented concomitant perirenal abscess with the same etiologic agent, and case 4 had a cutaneous injury 15 days before the symptoms' onset). One patient had history of urinary tract manipulation (transrectal ultrasoundguided biopsy of the prostate) and diabetes (case 6).

In 7 patients $(77,8 \%)$, the diagnosis was confirmed by transrectal ultrasound (Figure-1). One of the patients also performed a computed tomography that confirmed the presence of the abscess (Figure-2).



Figure 1 - Prostatic transrectal ultrasonography showing the prostatic abscess.

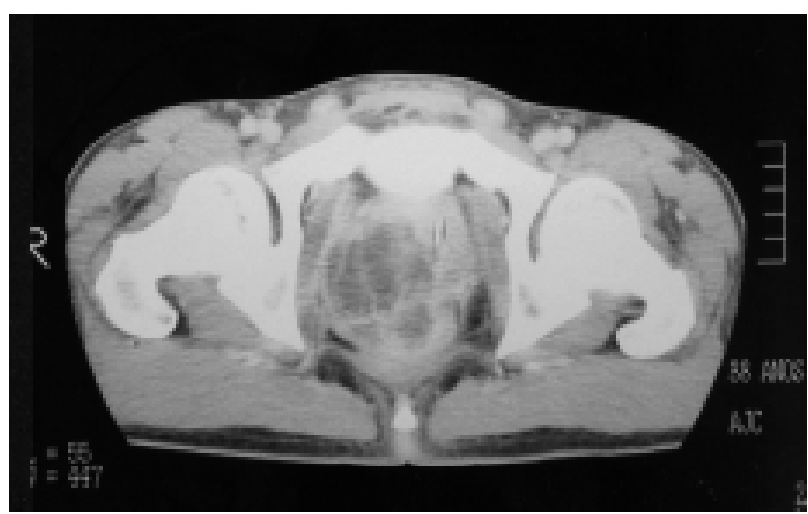

Figure 2 - Pelvic computed tomography showing an abscess in the prostate.

For 2 patients, the diagnosis was performed by abdominal ultrasound while still in the emergency unit (Figure-3). One patient did not perform ultrasonography and the diagnosis was done during an adenomectomy surgery.

All patients were treated with parenteral antibiotics during the hospital stay, with ciprofloxacin $400 \mathrm{mg}$ IV bid, in some cases associated to amikacin $500 \mathrm{mg}$ IV bid. Two patients also received metronidazole $500 \mathrm{mg}$ IV qid. In 2 cases it was necessary to alter the antibiotic regimen to ceftriaxone due to absence of clinical improvement. Seven patients $(77,8 \%)$ required adjuvant surgical treatment, and 2 were submitted to transurethral resection of the prostate (TURP), 4 to perineal pucture/drainage of the prostate, maintaining a silicone catheter for drainage, and 1 performed both procedures due to the periprostatic



Figure 3 - Prostatic abdominal ultrasonography showing the prostatic abscess. 


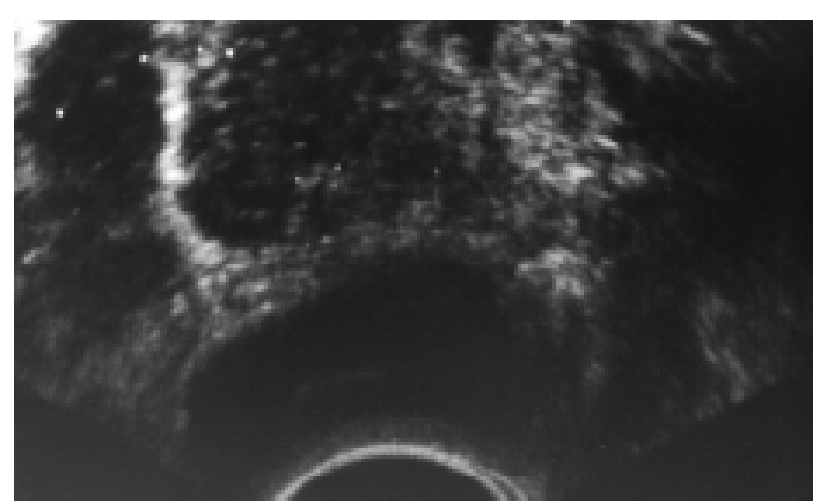

Figure 4 - Transrectal ultrasonography showing a prostatic abscess with periprostatic extension.

extension of the abscess. Two patients had extensions of the abscess to the space between the prostate and the rectum (Figure-4). The patient presenting concomitant perirenal abscess had the perirenal space drained by computed tomography-guided percutaneous route, with good outcome.

Two patients $(22,2 \%)$ presented microabscess and were treated exclusively with antibiotics, showing good results.

All patients had good outcomes, with no occurrence of sepsis or deaths in this series. Mean hospital stay was 11.2 days, and patients were discharged with oral antibiotics prescribed until totaling at least 21 treatment days, if not presenting residual abscess in clinical examination or control transrectal ultrasound.

In 7 patients surgically treated, there was Staphylococcus aureus growing in the material collected from the abscess in $4(57,1 \%)$ cases, Escherichia coli
Table 1 - Major symptoms and signs in patients presenting prostatic abscess.

\begin{tabular}{lr}
\hline Symptoms and Signs & $\begin{array}{c}\text { No. of } \\
\text { Patients (\%) }\end{array}$ \\
\hline Urinary retention & $7(77.8)$ \\
Fever & $9(100.0)$ \\
Dysuria and frequency & $9(100.0)$ \\
Leucocytosis & $8(88.9)$ \\
Leucocyturia & $9(100.0)$ \\
Fluctuation area in the prostate & $3(33.3)$ \\
Painful digital examination & $9(100.0)$ \\
Purulent urethral discharge & $1(11.1)$ \\
Previous urinary symptoms & $2(22.2)$ \\
Antibiotic use before hospitalization & $6(66.6)$ \\
\hline
\end{tabular}

in one case, Aeromonas aerophyla in one case, and Klebsiella pneumoniae in one case.

Major clinical data is presented in Tables-1 and 2.

\section{DISCUSSION}

When not adequately treated, the prostatic abscess may progress to sepsis and death. Thus, an accurate diagnostic and an efficient treatment are both required. Most published data about prostatic abscess are case reports, and there is no standardization of the diagnostic and therapeutic routine. In review articles, the summary of several individual experiences permits delineating some lines of action in cases of prostatic abscess $(1,2)$.

Table 2 - Demographic data and findings at the examination of patients with prostatic abscess.

\begin{tabular}{|c|c|c|c|c|c|c|c|c|c|}
\hline & $\# 1$ & $\# 2$ & \# 3 & $\# 4$ & $\# 5$ & \# 6 & $\# 7$ & \# 8 & \# 9 \\
\hline Age & 38 & 42 & 41 & 50 & 50 & 73 & 73 & 71 & 37 \\
\hline \multicolumn{10}{|l|}{ Onset of the } \\
\hline symptoms' (days) & 14 & 1 & 5 & 12 & 10 & 26 & 07 & 06 & 23 \\
\hline Culture & S. aureus & NP & S. aureus & S. aureus & S. aureus & E. coli & K. pneumoniae & NP & A. aerophyla \\
\hline Abscess TRUS & yes & yes & yes & yes & yes & yes & NP & yes & NP \\
\hline Urine culture & neg & neg & neg & neg & neg & neg & neg & NP & neg \\
\hline
\end{tabular}

TRUS = transrectal ultrasonography; $N P=$ not performed $;$ neg $=$ negative 
Various factors have influenced the shift of the epidemiological profile of prostatic abscess, such as routine and widespread use of broad-spectrum antibiotics to patients with lower urinary tract symptoms, without the investigation required (4); better control of chronic diseases allowing an increase in population longevity; therapeutic advances such as hemodialysis, organ transplants, chemotherapy, and immunosuppressive drugs, promoting longer survival, but also exposing to the risks of immunosuppression (4-7).

Finding spontaneous abscess drainage to the urethra (4), and peritonitis (8), is sporadic today. It is thought that the retrograde flow of contaminated urine within the prostate during micturition is the most prevalent pathogenic factor (9). Some authors suggest that prostatic abscess is a complication of bacterial prostatitis, acute or chronic, but the actual incidence and frequency of these events is not known (10). Bacterial haematogenous spread from distant foci was also described, such as from respiratory (bronchitis, otitis), digestive (appendicitis, diverticulitis), and urinary tracts (perirenal abscess), and from the skin (furuncles, abrasions). In these cases, germs like S. aureus, M. tuberculosis, E. coli e Candida sp. may be found.

In this series, patients presented a mean age comparable to that found in literature, where the most common age group is between the fifth and the sixth decades. However, cases in diverse age groups were described, including neonates (2). A higher prevalence of $S$. aureus was observed, opposed to the findings in literature indicating $E$. coli as the most prevalent bacteria (1). Only for 2 patients we have found a clear explanation for this fact, with the primary foci in the skin (injections drug use and cutaneous abscess).

Initially the disease manifests as dysuria, urgence, and frequency in $96 \%$ of the cases (1), fever in $30 \%$ to $72 \%(1,2,7)$, and urinary retention in $1 / 3$ of the patients $(2,7)$. We have observed a higher frequency of fever, urinary retention, dysuria and frequency in all patients (Table-1). There are reports of cases disclosed only at necropsy in children, and of 2 cases that did not present any symptom in a series of 269 cases (2). The most typical sign of prostatic ab- scess is fluctuation areas in the prostate by digital examination, although the results diverge between $16 \%$ (2) and $88 \%$ (1). This finding was observed in $33.3 \%$ of our patients. However, all presented painful prostate at digital exam, and leucocytosis and leucocyturia as well.

The diagnostic study of choice to assist the treatment and follow-up of patients with prostatic abscess is transrectal ultrasonography of the prostate. The most common finding is presence of one or more hypoechogenic areas, of several sizes, containing thick liquid primarily in the transition zone and in central zone of the prostate, permeated by hyperechogenic areas and distortion of the anatomy of the gland (7). In this series this finding was observed in $100 \%$ of the cases for which the examination was performed. Differential diagnosis should include prostatic cysts and neoplasia $(10,11)$. Computed tomography adds few benefits to transrectal ultrasonography for the diagnosis of prostatic abscess, especially when there are extraprostatic collections $(12,13)$.

Treatment implies in parenteral broad-spectrum antibiotic administration and abscess drainage. This may be performed by transrectal puncture (14) or transperineal ultrasound-guided, digital-guided puncture/drainage by perineal route, transurethral incision of the prostate, TURP, or open perineal drainage (15-18). There is a preference for minimally invasive procedures that may be performed under local anesthesia or sedation, and repeated if necessary. All methods have safety and efficiency reports (1$3,5,9,15-18)$.

Sending material to culture (pus, urine, blood, and/or a fragment of the prostate) is important in identifying the etiologic agent, especially for immunosuppressed patients, considering that they usually present uncommon germs $(19,20)$.

Lack of uniformity in antibiotics prescription occurs due to rareness of the disease, and there is no routine established for these cases. Most of the times the antibiotic was introduced by the on-call doctor in the emergency room.

Hospital stay period was prolonged, and most patients needed surgical treatment $(77,8 \%)$, showing that this disease deserves hospital care. The diagno- 
sis of prostatic abscess should be proposed for patients presenting fever and persistent irritative voiding symptoms despite antimicrobials use, for diabetics with protracted symptoms, for those with lower urinary tract symptoms and fever progressing to urinary retention, and after the performance of prostatic biopsy.

\section{REFERENCES}

1. Weinberger M, Cytron S, Servadio C, Block C, Rosenfeld JB, Pitlik SD: Prostatic abscess in the antibiotics era. Rev Infect Dis. 1988; 10: 239-49.

2. Granados EA, Caffaratti J, Farina L, Hocsman H: Prostatic abscess drainage: Clinical-sonography correlation. Urol Int. 1992; 48: 358-61.

3. Meares EM, Jr.: Prostatic abscess. J Urol. 1996; 129: 1281-2.

4. Gill SK, Gilson RJC, Rickards, D: Multiple prostatic abscesses presenting with urethral discharge. Genitourin Med. 1991; 67: 411-2.

5. Barozzi L, Pavlica P, Menchi I, De Matteis M, Canepari M: Prostatic abscess: diagnosis and treatment. AJR. 1998; 170: 753-7.

6. Cytron S, Weinberger M, Pitlik S, Servadio, C: Value of transrectal ultrasonography for diagnosis and treatment of prostatic abscess. Urology 1988; 32: 454-8.

7. Granados EA, Riley G, Salvador J, Vicente J: Prostatic abscess: Diagnosis and treatment. J Urol. 1992; 148: 80-2.

8. Mitchell RJ, Blake RJS: Spontaneous perforation of prostatic abscess with peritonitis. J Urol. 1972; 107: 622-3.

9. Trauzzi SJ, Kay CJ, Kaufman DG, Lowe FC: Management of prostatic abscess in patients with human immunodeficience syndrome. Urology 1994; 43: 62933.

10. Jameson RM: Prostatic abscess and carcinoma of the prostate. Br J Urol. 1968; 40: 288-92.

11. Rifkin MD: Ultrasonography of the lower genitourinary tract. Urol Clin North Am. 1985; 12: 645-56.

12. Thornill BA, Morehouse HT, Coleman P, Tretin JCH: Prostatic abscess: CT and sonographic findings. AJR. 1987; 148: 899-900.

13. Vaccaro JA, Belville WD, Kiesling Jr. VJ, Davis R: Prostatic abscess: Computerized tomography scanning as an aid to diagnosis and treatment. J Urol. 1986; 136: 1318-9.

14. Chaabouni MN, Pfeifer P, Ferrandis $P$, Chokairi $P$, D'Ardalhon T, Dumas JP et al.: Place de ponction transrectale écho-guidée dans le traitement des abcès prostatiques. Ann Urol. 1994; 28: 24-7.

15. Lopez VM, Castro VF, Pallas MP, Garcia JA, Gonzalez PC: Drenaje transperineal de un absceso prostático. Arch Esp de Urol. 1994; 47: 290-1.

16. Kinahan TJ, Goldenberg SL, Ajzen AS, Cooperberg PL, English, RA: Transurethral resection of prostatic abscess under sonographic guidance. Urology. 1991; 37: 475-7.

17. Bachor R, Gottfried HW, Hautmann, R: Minimal invasive therapy of prostatic abscess by transrectal ultrasound-guided perineal drainage. Eur Urol. 1995; 28 : 320-4.

18. Llanes JV, Carbonell CL, Toro AOA, Mas AG: Abscesos prostáticos: tratamiento percutáneo. Arch Esp de Urol. 1991; 44: 69-72.

19. Sanjuan FG, Cidre MJ, Rodríguez RR, Elias MJP, Santos VG, Escudero JAR: Absceso prostático tuberculoso en síndrome de inmunodeficiencia adquirida. Arch Esp de Urol. 1997; 50: 393-5.

20. Learmonth DJ, Philp NH: Salmonella prostatic abscess. Br J Urol. 1988; 61: 163.

Received: August 7, 2002

Accepted after revision: January 9, 2003

\author{
Correspondence address: \\ Dr. Paulo Oliveira \\ Serviço de Urologia, Hospital São Rafael \\ Av. São Rafael, 2152 / 6o. Andar / Sala 9 \\ Salvador, BA, 41256-900, Brazil \\ Fax: + $5571399-6513$ \\ E-mail: paulourologia@hotmail.com
}

